\title{
OPEN Adsorption of an anionic dye (Congo red) from aqueous solutions by pine bark
}

\begin{abstract}
Khaoula Litefti ${ }^{1,2}$, M. Sonia Freire ${ }^{1}$, Mostafa Stitou$^{2} \&$ Julia González-Álvarez $\mathbb{\mathbb { D }}^{1 *}$
Pinus pinaster bark, an abundant by-product from the timber industry, has been studied as a potential low-cost adsorbent for the removal of Congo red (CR) dye from wastewaters. Surface morphological and physico-chemical characteristics of pine bark were analysed using Fourier transform infrared (FTIR) spectroscopy, scanning electron microscopy (SEM), determination of the point of zero charge $\left(\mathrm{pH}_{\mathrm{PzC}}\right)$ and elemental analysis. Assays were performed to determine the wavelength for the maximum absorbance and the stability with time of $\mathrm{CR}$ solutions depending on concentration and/or $\mathrm{pH}$, which resulted to be a very significant parameter. Adsorption studies were conducted on batch mode to study the effect of contact time (till 7 days), $\mathrm{pH}(2-9)$, adsorbent dosage $\left(1-10 \mathrm{~g} \mathrm{~L}^{-1}\right)$ and temperature $\left(25-60^{\circ} \mathrm{C}\right)$. The bark adsorption capacity at equilibrium varied between 0.3 and $1.6 \mathrm{mg} \mathrm{g}^{-1}$ and the equilibrium adsorption percentage between 23.4 and $100 \%$ depending on adsorbent dosage, temperature and $\mathrm{pH}$ at an initial CR concentration of $5 \mathrm{mg} \mathrm{L}^{-1}$. Kinetic data for the removal of CR by pine bark were best fitted by the pseudo-second-order kinetic model. The equilibrium data fitted well with the Freundlich model. Thermodynamic analysis indicated that the adsorption process is exothermic and spontaneous.
\end{abstract}

The textile industries use dyes to colour their products and consume substantial volumes of water. As a result, they generate considerable amounts of coloured wastewaters ${ }^{1}$. It is estimated that more than 100000 commercially available dyes with over $7 \times 10^{5} \mathrm{t}$ of dyestuff are produced annually ${ }^{2,3}$ and $5-10 \%$ of dyestuffs are lost in the industrial effluents ${ }^{4,5}$. The direct discharge of these effluents into natural streams and rivers causes important environmental problems due to their contribution to high organic loading, toxicity and contamination by colour ${ }^{6}$, reducing light penetration and photosynthesis which affects the aquatic life ${ }^{7}$. In addition, most of dyes are either toxic or mutagenic and carcinogenic ${ }^{8-10}$.

Conventional technologies for removing dyes from industrial effluents include chemical, biological and physicochemical treatments ${ }^{11,12}$. Adsorption on activated carbons is one of the most efficient processes for wastewater treatment ${ }^{13-15}$, however, the current goal is substituting activated carbons for efficient, low-cost and highly available biosorbents. Thus, many studies have been performed to investigate the use of low-cost adsorbents for the removal of dyes from aqueous solutions ${ }^{16-18}$. Agricultural wastes or by-products have been used without or with a light processing, reducing production costs by using renewable, easily available and cheap raw materials and eliminating energy costs associated with thermal treatment. However, other biomass materials have been modified by physical or chemical treatments, such as carbonization or the use of chemical activating agents, to achieve better adsorption characteristics and to make them more effective ${ }^{16}$.

The treatment of dye effluents is difficult due to their different synthetic origins and aromatic structures; moreover, they are not biodegradable. Congo red (CR) is a benzidine-based anionic diazo dye that can cause allergic reactions and can be metabolized to benzidine, a carcinogenic product ${ }^{19}$. Depending on $\mathrm{pH}$, various molecular structures of CR can be present in aqueous solution ${ }^{20}$, which hinders its elimination.

Pinus pinaster bark is an abundant by-product from the timber industry in Galicia (NW of Spain), mainly used as fuel or in horticulture. In previous works, the removal of metal cations and phenol from aqueous solutions using Pinus pinaster bark has been demonstrated ${ }^{21,22}$. The aim of the present work was to test for the first time, as far as we know, the use of Pinus pinaster bark for the removal of CR from aqueous solutions. An effective use of pine bark as biosorbent of $\mathrm{CR}$ and other dyes from wastewaters would contribute not only to its valorisation but

${ }^{1}$ Department of Chemical Engineering, School of Engineering, Universidade de Santiago de Compostela, Rúa Lope Gómez de Marzoa, s/n, 15782, Santiago de Compostela, Spain. ${ }^{2}$ Department of Chemistry, Faculty of Sciences, University Abdelmalek Essaâdi, B.P. 2121, Mhanech II, 93002, Tétouan, Morocco. *email: julia.gonzalez@usc.es 

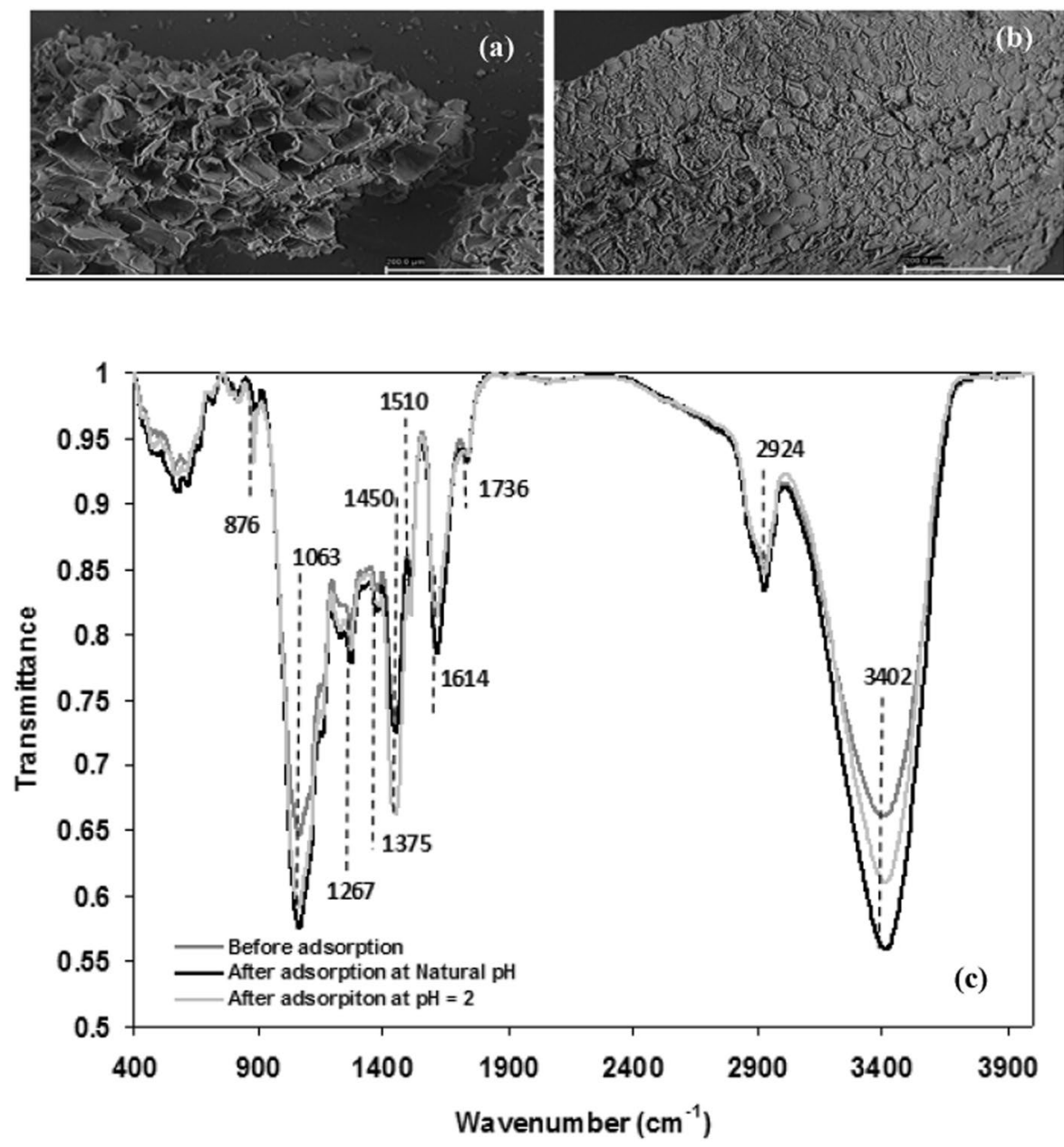

Figure 1. SEM images of Pinus pinaster bark (a) before and (b) after Congo red adsorption and (c) FTIR spectra of pine bark before and after Congo red adsorption at $\mathrm{pH}=6$ (natural) and $\mathrm{pH}=2$.

also to process sustainability. Batch adsorption experiments were carried out to analyse the influence of contact time, $\mathrm{pH}$, adsorbent dosage and temperature on $\mathrm{CR}$ adsorption by pine bark. The effect of $\mathrm{pH}$ was particularly emphasized and, thus, the stability of the dye solutions at different initial concentration and $\mathrm{pH}$ was also studied. In addition, adsorption kinetics and equilibrium were analysed applying mathematical models to experimental data.

\section{Materials and Methods}

Adsorbent. Pinus pinaster bark was supplied by the company Aserpal S.A. (Grupo Losán S.A., Galicia, NW Spain) specialized in the elaboration of fine wood surfaces. It was air-dried to a moisture content close to equilibrium (approximately 20\%, on dried basis). It was ground in a hammer mill and the fraction of particles with size between 0.5 and $2 \mathrm{~mm}$ was selected. In order to extract soluble compounds that could colour the water and interfere with the analytical determination of the dye, the bark was pre-treated twice with water at $25^{\circ} \mathrm{C}$ for $4 \mathrm{~h}$ at a solid/liquid ratio of $1 / 10\left(\mathrm{~g} \mathrm{~mL}^{-1}\right)$. The bark, once filtered and air-dried, was stored in plastic bags until their use for analysis and adsorption experiments. It was verified that after the second pre-treatment stage the filtrate came out colourless.

Chemicals. Congo red (CR) (Direct Red 28, C.I. 22120, azo dye, $\mathrm{C}_{32} \mathrm{H}_{22} \mathrm{~N}_{6} \mathrm{Na}_{2} \mathrm{O}_{6} \mathrm{~S}_{2}$, molecular weight 696.7) was selected as anionic dye. The $\mathrm{pH}$ was adjusted with $0.1 \mathrm{M} \mathrm{NaOH}$ or $0.1 \mathrm{M} \mathrm{HCl}$ solutions. All chemicals were of analytical grade. The dye solutions $\left(5-100 \mathrm{mg} \mathrm{L}^{-1}\right)$ were prepared by diluting a stock CR solution $\left(100 \mathrm{mg} \mathrm{L}^{-1}\right)$ with distilled water.

Characterization of the adsorbent. The carbon, hydrogen and nitrogen, contents of Pinus pinaster bark were determined using an Elemental Combustion System (Thermo Finnigan Flash 1112 model). The O content was calculated by difference. The ash content was determined according to the ASTM D1102-84 norm ${ }^{23}$.

The morphological features and surface characteristics of the adsorbent before and after CR adsorption were obtained by scanning electron microscopy (SEM) using a ZEISS EVO LS 15 microscope (Germany) at 200 magnifications. 


\begin{tabular}{|c|c|c|c|}
\hline \multicolumn{3}{|c|}{ Wavenumber $\left(\mathrm{cm}^{-1}\right)$} & \multirow[b]{3}{*}{ Assignments $^{\mathrm{a}}$} \\
\hline \multirow{2}{*}{$\begin{array}{l}\text { Before } \\
\text { adsorption }\end{array}$} & \multicolumn{2}{|c|}{ After adsorption } & \\
\hline & Natural pH & $\mathrm{pH}=2$ & \\
\hline 3402 & 3413 & 3410 & $\mathrm{O}-\mathrm{H}$ and $\mathrm{N}-\mathrm{H}$ stretching \\
\hline 2924 & 2925 & 2925 & Aliphatic C-H stretching \\
\hline 1736 & 1736 & 1736 & Ketone/aldehyde CO stretching \\
\hline 1614 & 1616 & 1612 & $\mathrm{C}=\mathrm{O}$ stretching \\
\hline 1510 & 1510 & 1510 & Secondary amine groups \\
\hline 1450 & 1450 & 1450 & Aromatic ring vibration \\
\hline 1375 & 1375 & 1383 & C-H bending \\
\hline 1317 & 1317 & 1315 & $\mathrm{CH}_{2}$ wagging \\
\hline 1267 & 1267 & 1267 & $-\mathrm{SO}_{3}$ stretching \\
\hline 1157 & 1155 & 1155 & C-O-C asymmetrical stretching \\
\hline 1063 & 1063 & 1063 & $\mathrm{C}-\mathrm{O}, \mathrm{CC}$, and $\mathrm{C}-\mathrm{C}-\mathrm{O}$ stretching \\
\hline 876 & 876 & 876 & Glycosidic linkage \\
\hline
\end{tabular}

Table 1. FTIR spectra peaks assignment. ${ }^{a}$ Yaneva and Georgieva ${ }^{18}$.

FTIR spectra of the adsorbent before and after adsorption were recorded by triplicate with a Varian FT-IR 670 model in the range of $4000-400 \mathrm{~cm}^{-1}$. Each sample was finely ground, mixed with $\mathrm{KBr}$ at a ratio of $1 / 50(\mathrm{mg} / \mathrm{mg})$ and pressed to prepare the pellet.

The $\mathrm{pH}$ of the point of zero charge $\left(\mathrm{pH}_{\mathrm{PZC}}\right)$ of Pinus pinaster bark was determined according to the procedure described by Moreno-Castilla et al. ${ }^{24}$.

Stability of CR dye solutions. In order to determine the wavelength for the value of maximum absorbance $\left(\lambda_{\max }\right)$ and its change with $\mathrm{pH}$, a CR solution of $5 \mathrm{mg} \mathrm{L}^{-1}$ was used and $\mathrm{pH}$ was modified from 2 to 12 using $0.1 \mathrm{M}$ $\mathrm{HCl}$ or $0.1 \mathrm{M} \mathrm{NaOH}$. Then, the visible absorption spectra of the solutions were recorded at room temperature with a UV-Vis spectrophotometer (V-630 UV/VIS JASCO, Japan).

To study dye stability, experiments were carried out at $25^{\circ} \mathrm{C}$ by contacting $100 \mathrm{~mL}$ of the dye solution at the selected $\mathrm{pH}$, natural $\mathrm{pH}(\mathrm{pH}=6)$ or $\mathrm{pH}=2$, and at different concentrations $\left(5,50\right.$ or $\left.100 \mathrm{mg} \mathrm{L}^{-1}\right)$ in a thermostatic orbital water bath shaker (UNITRONIC-OR SELECTA, Spain) at a shaking rate of $100 \mathrm{rpm}$. Samples were withdrawn at predetermined times (1,2,6 and 7 days) and the absorbance was measured spectrophotometrically at the $\lambda_{\max }$ previously determined. The $\mathrm{pH}$ of dye solutions was adjusted by using $0.1 \mathrm{M} \mathrm{HCl}$ and $0.1 \mathrm{M} \mathrm{NaOH}$ solutions.

Adsorption kinetic experiments. Batch adsorption experiments were conducted in a thermostatic orbital water bath shaker (UNITRONIC-OR SELECTA, Spain) at a shaking rate of $100 \mathrm{rpm}$. $100 \mathrm{~mL}$ of the dye solution $\left(5 \mathrm{mg} \mathrm{L}^{-1}\right)$ were put in contact with the selected amount of adsorbent in stoppered Erlenmeyer flasks and the effect of contact time, solution initial $\mathrm{pH}(2-9)$, adsorbent dosage $\left(1,5\right.$ and $\left.10 \mathrm{~g} \mathrm{~L}^{-1}\right)$ and temperature $(25,40$ and $60^{\circ} \mathrm{C}$ ) on the adsorption process was studied using the one-factor-at-a-time method. Solution $\mathrm{pH}$ changed during the adsorption process from an initial $\mathrm{pH}$ of 2, 6 and 9 to a final $\mathrm{pH}$ of 2.2, 4.5 and 4.7, respectively, due to variations of the functional groups in pine bark.

At the selected times, the samples were withdrawn, the suspensions were centrifuged and the residual dye concentration on the supernatant was determined from the calibration curve by measuring the absorbance at the $\lambda_{\max }$ previously determined. Measurements were made in duplicate and the results averaged.

The amount of dye adsorbed onto pine bark at time $\mathrm{t}$, or adsorption capacity, $\mathrm{q}_{\mathrm{t}}\left(\mathrm{mg} \mathrm{g}^{-1}\right)$, was calculated by the following mass balance relationship:

$$
q_{t}=\frac{\left(C_{0}-C_{t}\right) V}{m}
$$

where $\mathrm{C}_{0}$ is the initial dye concentration $\left(\mathrm{mg} \mathrm{L}^{-1}\right), \mathrm{C}_{\mathrm{t}}$ is the dye concentration at any time $\mathrm{t}, \mathrm{V}$ is the volume of solution (L) and $\mathrm{m}$ is the mass of adsorbent ( $\mathrm{g}$ of oven dried (o.d.) pine bark). The dye removal efficiency was determined as:

$$
\% \text { Adsorption }=100\left(\frac{C_{0}-C_{t}}{C_{0}}\right)
$$

Adsorption equilibrium experiments. Equilibrium adsorption studies were conducted in a thermostatic orbital water bath shaker (UNITRONIC-OR SELECTA, Spain) at a shaking rate of $100 \mathrm{rpm}$ by contacting at $25^{\circ} \mathrm{C}$ and natural $\mathrm{pH}, 100 \mathrm{~mL}$ of the dye solutions of different initial concentrations, from 5 to $100 \mathrm{mg} \mathrm{L}^{-1}$, with $1 \mathrm{~g}$ of pine bark (on dried basis) for 7 days. This time was considered enough to reach equilibrium.

Theory. Adsorption Kinetics. The Lagergren's first order kinetic equation was applied in its linear form: 

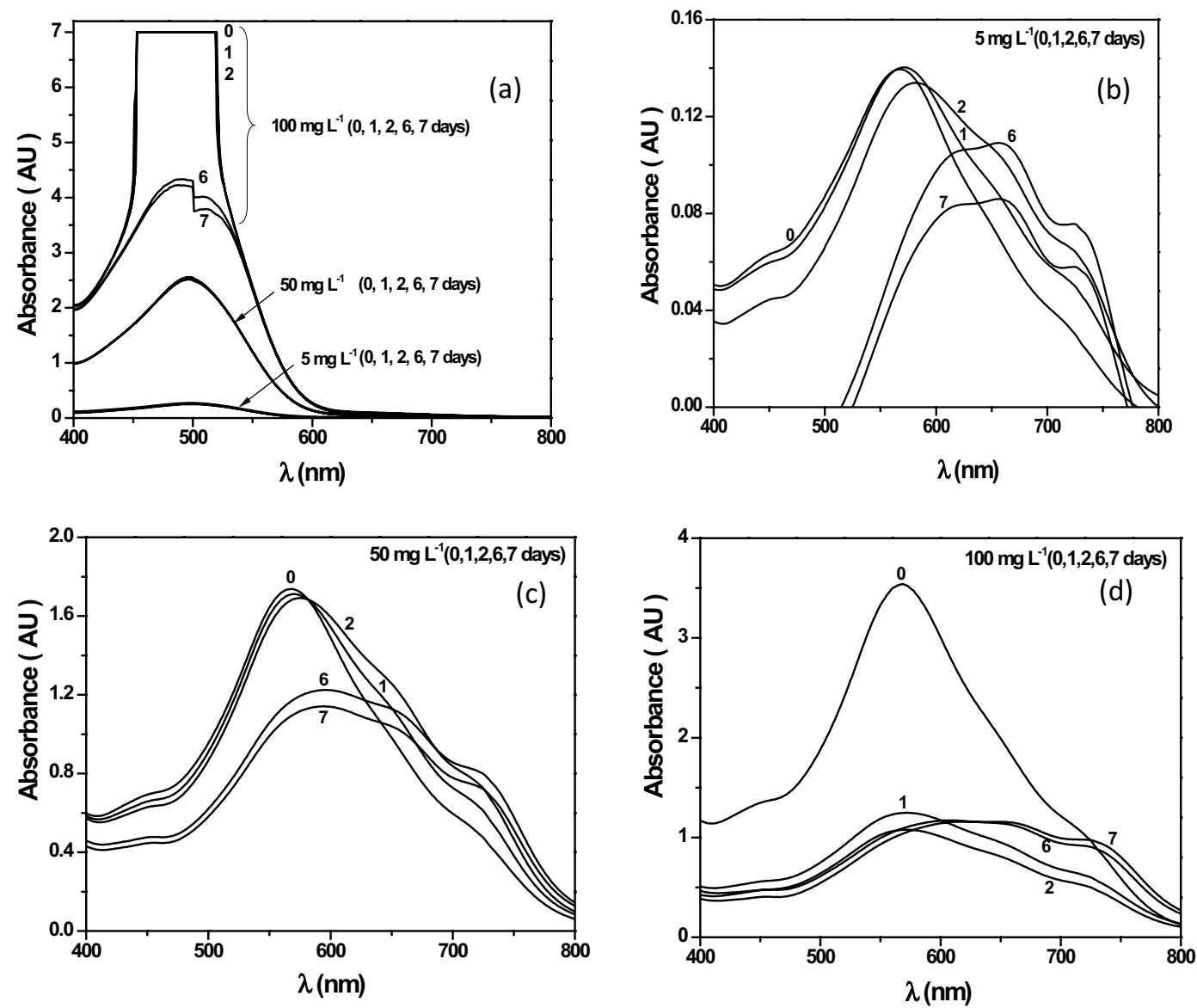

Figure 2. Stability of Congo red solutions with time at different initial concentrations (a) natural $\mathrm{pH},(\mathbf{b})$ $\mathrm{pH}=2$ and $5 \mathrm{mg} \mathrm{L}^{-1}$, (c) $\mathrm{pH}=2$ and $50 \mathrm{mg} \mathrm{L}^{-1}$ and $(\mathbf{d}) \mathrm{pH}=2$ and $100 \mathrm{mg} \mathrm{L}^{-1}$.

$$
\log \left(q_{e}-q_{t}\right)=\log \left(q_{e}\right)-\frac{k_{1}}{2.303} t
$$

where $\mathrm{q}_{\mathrm{t}}$ and $\mathrm{q}_{\mathrm{e}}$ are the amounts of dye adsorbed $\left(\mathrm{mg} \mathrm{g}^{-1}\right)$ at $\mathrm{t}$ and equilibrium time (h), respectively, and $\mathrm{k}_{1}$ represents the first-order rate constant $\left(\mathrm{h}^{-1}\right)$.

The adsorption data were also analysed in terms of the Ho's pseudo-second-order model ${ }^{25}$ in the following form:

$$
\frac{t}{q_{t}}=\frac{1}{k_{2} q_{e}^{2}}+\frac{1}{q_{e}} t
$$

With $\mathrm{k}_{2}\left(\mathrm{~g} \mathrm{mg}^{-1} \mathrm{~h}^{-1}\right)$, the pseudo-second-order rate constant. The initial sorption rate $\left(\mathrm{h}_{0}, \mathrm{mg} \mathrm{g}^{-1} \mathrm{~h}^{-1}\right)$, was determined when $t$ approaches to zero, as follows:

$$
h_{0}=k_{2} q_{e}^{2}
$$

Adsorption mechanism. Intra-particle diffusion model based on the model proposed by Weber and Morris ${ }^{26}$ is commonly used for identifying the adsorption mechanism for design purposes. For most adsorption processes, the uptake varies almost proportionately with $\mathrm{t}^{1 / 2}$ rather than with the contact time and can be represented as follows:

$$
q_{t}=K_{i d} t^{1 / 2}+I
$$

where $\mathrm{I}$ is the intercept and $\mathrm{K}_{\mathrm{id}}$ is the rate constant of intra-particle diffusion ( $\mathrm{mg} \mathrm{g}^{-1} \mathrm{~h}^{-1 / 2}$ ).

Thermodynamic study. Thermodynamic parameters such as Gibb's free energy $\left(\Delta \mathrm{G}^{\circ}\right)$, enthalpy change $\left(\Delta \mathrm{H}^{\circ}\right)$ and entropy change $\left(\Delta S^{\circ}\right)$ for the adsorption of dye on pine bark have been determined by using the following equations: 

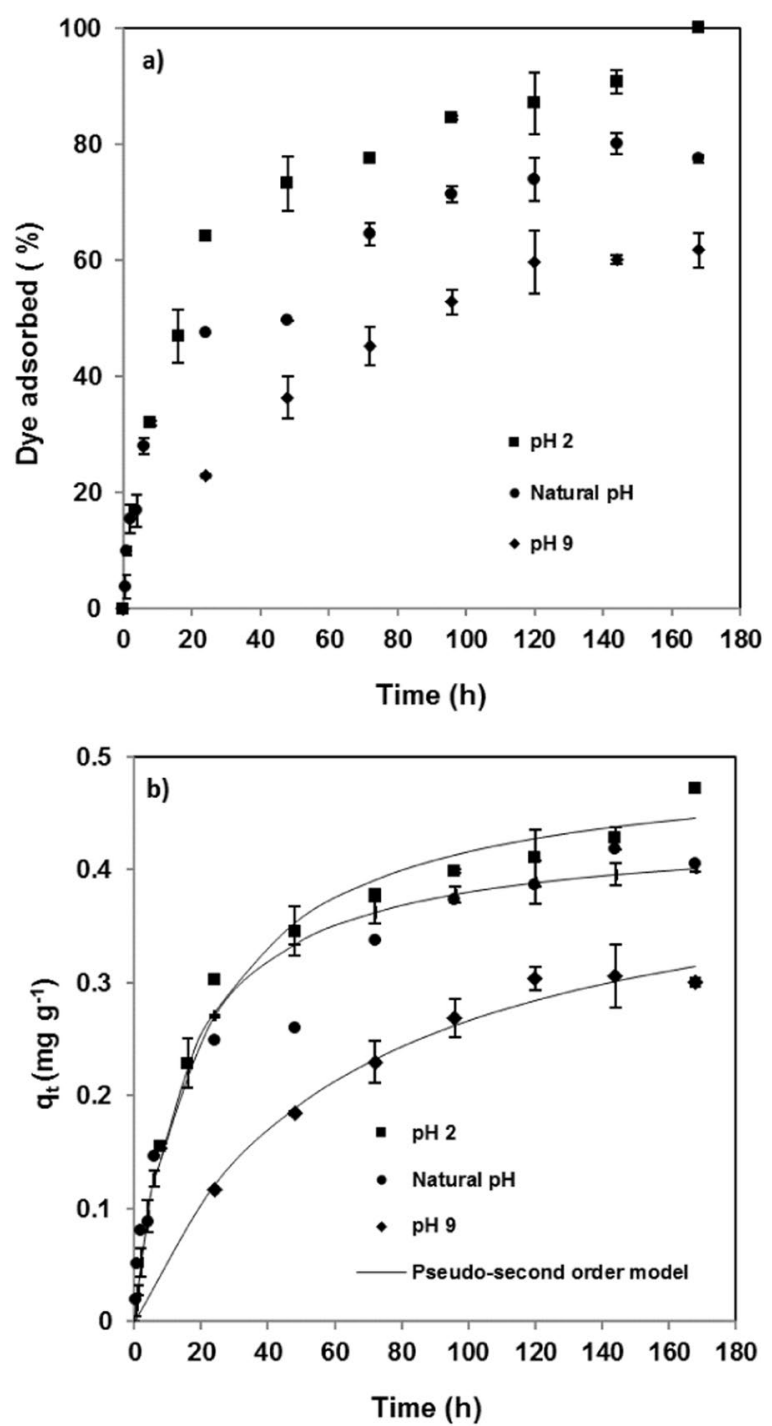

Figure 3. Effect of initial $\mathrm{pH}$ on (a) removal efficiency and (b) adsorption capacity. Experimental data and fitting to pseudo-second order kinetic model (temperature $=25^{\circ} \mathrm{C}$; initial dye concentration $=5 \mathrm{mg} / \mathrm{L}$; adsorbent dose $=10 \mathrm{gL}^{-1}$ )

$$
\begin{gathered}
\Delta G^{0}=\Delta H^{0}-T \Delta S^{0} \\
\ln \left(\frac{q_{e}}{C_{e}}\right)=\frac{\Delta S^{0}}{R}-\frac{\Delta H^{0}}{R}\left(\frac{1}{T}\right)
\end{gathered}
$$

where $\mathrm{C}_{\mathrm{e}}$ is the equilibrium concentration $\left(\mathrm{mg} \mathrm{L}^{-1}\right)$, T is temperature $(\mathrm{K})$ and $\mathrm{R}$ is the ideal gas constant.

Adsorption Isotherm. To determine the adsorption isotherms, two commonly used models, the Freundlich and Langmuir equations, were applied to explain the dye-Pinus pinaster bark interactions.

The Langmuir isotherm Eq. (9) assumes monolayer adsorption onto a surface containing a finite number of adsorption $\operatorname{sites}^{27}$. This isotherm can be represented in a linear form as follows:

$$
\frac{C_{e}}{q_{e}}=\left(\frac{1}{K_{a} q_{m}}\right)+\frac{C_{e}}{q_{m}}
$$

where $\mathrm{q}_{\mathrm{m}}$ is the maximum adsorption capacity $\left(\mathrm{mg} \mathrm{g}^{-1}\right)$ and $K_{a}$ is the constant related to the energy of adsorption $\left(\mathrm{L} \mathrm{mg}^{-1}\right)$.

The essential features of the Langmuir isotherm may be expressed in terms of equilibrium parameter or separation factor, $\mathrm{R}_{\mathrm{L}}$, which is a dimensionless constant: 


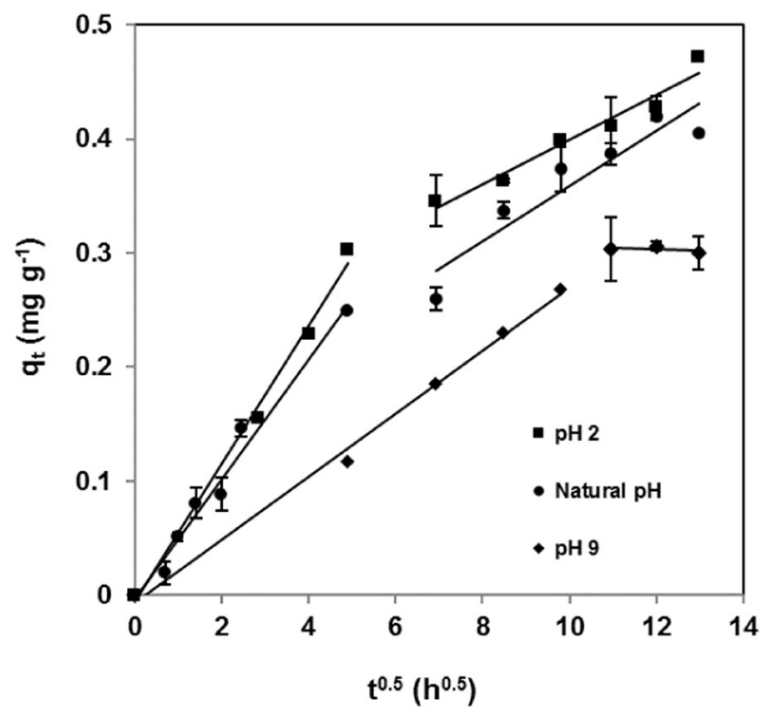

Figure 4. Application of intra-particle diffusion model for Congo red adsorption by Pinus pinaster bark (temperature $=25^{\circ} \mathrm{C}$; initial dye concentration $=5 \mathrm{mg} \mathrm{L}^{-1}$; adsorbent dose $=10 \mathrm{~g} \mathrm{~L}^{-1}$ ).

\begin{tabular}{|c|c|c|c|c|c|c|}
\hline \multicolumn{7}{|c|}{ Pseudo-second-order model } \\
\hline & & & Equilibrium Adsorption & \multirow{2}{*}{$\begin{array}{l}\mathrm{k}_{2} \\
\left(\mathrm{~g} \mathrm{mg}^{-1} \mathrm{~h}^{-1}\right)\end{array}$} & \multirow{2}{*}{\begin{tabular}{|l|}
$\mathrm{qe}$ \\
$\left(\mathrm{mg} \mathrm{g}^{-1}\right)$ \\
\end{tabular}} & \multirow{2}{*}{$\mathrm{R}^{(\mathrm{a})}$} \\
\hline & & & $\%$ & & & \\
\hline & & 2 & 94.4 & 0.101 & 0.50 & 0.992 \\
\hline $\mathrm{pH}^{(\mathrm{b})}$ & & 6 (Natural) & 76.6 & 0.156 & 0.44 & 0.987 \\
\hline & & 9 & 61.9 & 0.038 & 0.43 & 0.982 \\
\hline & & 1 & 29.0 & 0.004 & 2.51 & 0.911 \\
\hline Adsorbent dosage & $\left(\mathrm{g} \mathrm{L}^{-1}\right)^{(\mathrm{c})} \mathrm{pH}=6$ (Natural) & 5 & 66.8 & 0.015 & 1.00 & 0.975 \\
\hline & & 10 & 76.6 & 0.156 & 0.44 & 0.987 \\
\hline & & 1 & 24.5 & 0.004 & 2.00 & 0.870 \\
\hline Adsorbent dosage & $\left(\mathrm{g} \mathrm{L}^{-1}\right)^{(\mathrm{c})} \mathrm{pH}=2$ & 5 & 80.0 & 0.008 & 1.25 & 0.955 \\
\hline & & 10 & 94.4 & 0.101 & 0.50 & 0.992 \\
\hline & & 25 & 94.5 & 0.219 & 0.50 & 1.000 \\
\hline Temperature $\left({ }^{\circ} \mathrm{C}\right)$ & & 40 & 89.7 & 0.363 & 0.46 & 1.000 \\
\hline & & 60 & 79.7 & 0.605 & 0.41 & 1.000 \\
\hline Intra-particle dif & fusion model & & & & & \\
\hline & First stage & & & Second stage & & \\
\hline & $K_{1 d}\left(\mathrm{mg} \mathrm{g}^{-1} h^{0.5}\right)$ & $I_{1}\left(\mathrm{mg} \mathrm{g}^{-1}\right)$ & $\mathbf{R}^{(\mathbf{a})}$ & $K_{2 d}\left(\mathrm{mg} \mathrm{g}^{-1} h^{0.5}\right)$ & $I_{2}\left(\mathrm{mg} \mathrm{g}^{-1}\right)$ & $\mathbf{R}^{(\mathbf{a})}$ \\
\hline $\mathrm{pH}=2$ & 0.0605 & -0.006 & 0.994 & 0.0198 & 0.202 & 0.954 \\
\hline $\mathrm{pH}=6$ (Natural) & 0.0525 & -0.003 & 0.978 & 0.0243 & 0.116 & 0.881 \\
\hline $\mathrm{pH}=9$ & 0.0276 & -0.006 & 0.995 & - & - & - \\
\hline
\end{tabular}

Table 2. Pseudo-second-order and intra-particle diffusion kinetic parameters for the removal of Congo red by pine bark. ${ }^{(\mathrm{a})} \mathrm{p}<0.0001 .{ }^{(\mathrm{b})}$ Adsorbent dosage $=10 \mathrm{~g} \mathrm{~L}^{-1}$; Temperature $=25^{\circ} \mathrm{C}$. ${ }^{\text {(c) }}$ Temperature $=25^{\circ} \mathrm{C}$. (d) Adsorbent dosage $=10 \mathrm{~g} \mathrm{~L}^{-1}$; Natural $\mathrm{pH}$.

$$
R_{L}=\frac{1}{1+K_{a} C_{0}}
$$

The value of $R_{L}$ indicates the adsorption nature to be either unfavourable $\left(R_{L}>1\right)$, linear $\left(R_{L}=1\right)$, favourable $\left(0<\mathrm{R}_{\mathrm{L}}<1\right)$ or irreversible $\left(\mathrm{R}_{\mathrm{L}}=0\right)$.

The Freundlich adsorption isotherm ${ }^{28}$, which assumes that adsorption occurs on heterogeneous surfaces, can be expressed linearly as: 

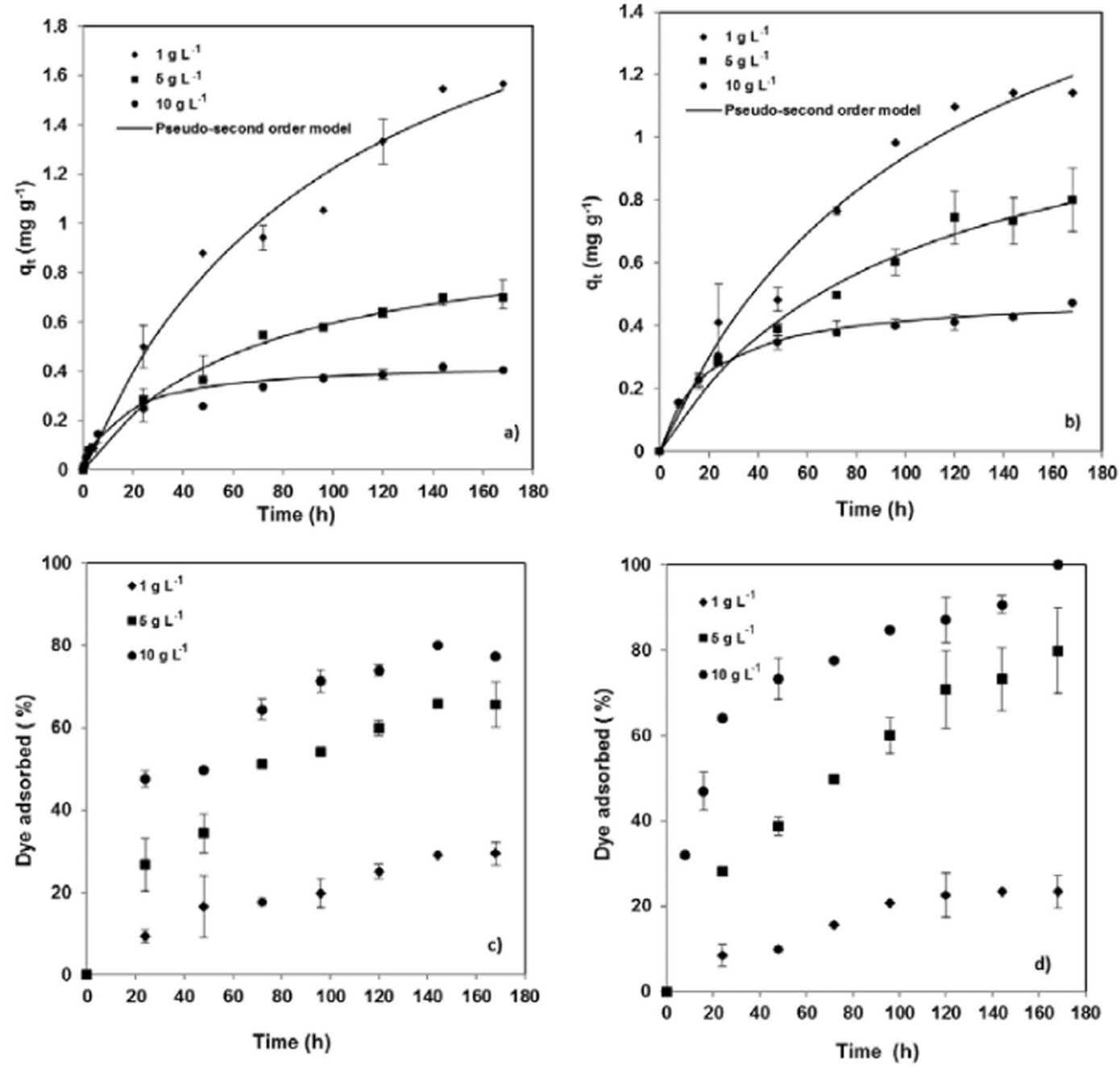

Figure 5. Effect of the pine bark dosage on Congo red adsorption capacity at (a) natural $\mathrm{pH}$ and (b) $\mathrm{pH}=2$ and on removal efficiency at (c) natural $\mathrm{pH}$ and $(\mathbf{d}) \mathrm{pH}=2$ (temperature $=25^{\circ} \mathrm{C}$; initial dye concentration $\left.=5 \mathrm{mg} \mathrm{L}^{-1}\right)$. Experimental data and fitting to pseudo-second order kinetic model.

$$
\ln q_{e}=\ln K_{f}+\frac{1}{n} \ln C_{e}
$$

where $\mathrm{K}_{\mathrm{f}}$ and $\mathrm{n}$ are the isotherm constants which indicate the adsorption capacity and intensity, respectively.

\section{Results and Discussion}

Adsorbent characterization. The chemical composition of the adsorbent was analysed, and the results revealed that contains: $\mathrm{C}, 48.2 \%, \mathrm{O}, 45.1 \%, \mathrm{H}, 6.5 \%$ and $\mathrm{N}, 0.2 \%(\% \mathrm{w} / \mathrm{w})$. As any lignocellulosic material, the main content corresponded to carbon, whereas nitrogen and ash contents $(0.45 \%, \mathrm{w} / \mathrm{w})$ were very low.

SEM analysis is widely used to study the morphological features and surface characteristics of adsorbents. It reveals their surface texture and porosity and plays an important role in determining the surface availability for adsorption ${ }^{29}$. Thus, the SEM micrographs of Pinus pinaster bark before and after Congo red adsorption are presented in Fig. 1a,b, respectively. It was observed that the adsorption caused significant changes in the surface texture of the bark. Before adsorption, its surface was heterogeneous, evidencing the presence of pores with different shapes and sizes. However, after dye adsorption a thick layer of dye covering the pores was observed and, as a result, the surface presented a smooth morphology. This is in good agreement with other authors who also found surface morphological changes after dye loading ${ }^{30}$.

Pinus pinaster bark, as other agro-industrial materials, contains polar functional groups such as alcohols, aldehydes, ketones, carboxylic, phenolic and others, constituting active sites for the adsorption of dye molecules. To analyse the effect of dye adsorption on these functional groups, FTIR spectra of pine bark before and after adsorption were compared at two of the $\mathrm{pH}$ essayed, natural $\mathrm{pH}(\mathrm{pH}=6)$ and $\mathrm{pH}=2$ (Fig. 1c). The peak assignments according to literature ${ }^{18,31}$ are presented in Table 1. As shown in Fig. 1c, the spectra have similar characteristics, even though some peaks are shifted, or their intensities changed. Thus, after CR adsorption, the absorption band at $3402 \mathrm{~cm}^{-1}$ shifted to higher wavenumbers and increased in intensity, more significantly at the 


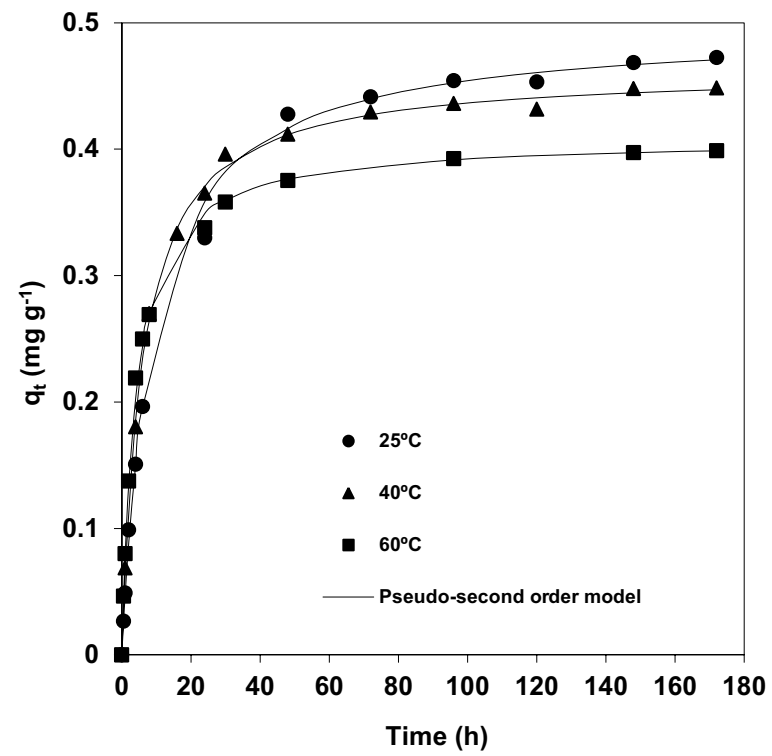

Figure 6. Effect of temperature on Congo red adsorption capacity of Pinus pinaster bark at natural pH. Experimental data and fitting to pseudo-second order kinetic model (initial dye concentration $=5 \mathrm{mg} \mathrm{L}^{-1}$; adsorbent dose $=10 \mathrm{gL}^{-1}$ ).

\begin{tabular}{|c|c|c|c|c|c|}
\hline \multicolumn{6}{|c|}{ Isotherm models $\left(25^{\circ} \mathrm{C}\right.$, Natural $\mathrm{pH}$ and $\left.10 \mathrm{~g} \mathrm{~L}^{-1}\right)$} \\
\hline$q_{m}\left(\mathrm{mg} \mathrm{g}^{-1}\right)$ & $\mathrm{K}_{\mathrm{a}}\left(\mathrm{L} \mathrm{mg}^{-1}\right)$ & $\mathbf{R}^{2}$ & $K_{\mathrm{F}}$ & $\mathbf{n}$ & $\mathbf{R}^{2}$ \\
\hline \multicolumn{3}{|l|}{ Langmuir isotherm } & \multicolumn{3}{|c|}{ Freundlich isotherm } \\
\hline 3.92 & 0.26 & 0.98 & 0.96 & 2.77 & 0.99 \\
\hline \multicolumn{6}{|c|}{ Thermodynamic parameters $\left(\mathrm{C}_{0}=5 \mathrm{mg} \mathrm{L}^{-1}\right.$, Natural $\mathrm{pH}$ and $\left.10 \mathrm{gL}^{-1}\right)$} \\
\hline Temperature (K) & $\Delta \mathrm{G}^{\circ}\left(\mathrm{kJ} \mathrm{mol}{ }^{-1}\right)$ & \multicolumn{2}{|c|}{$\Delta \mathbf{H}^{\circ}\left(\mathrm{kJ} \mathrm{mol}^{-1}\right)$} & \multicolumn{2}{|c|}{$\Delta \mathrm{S}^{\circ}\left(\mathrm{kJ} \mathrm{mol}^{-1}\right)$} \\
\hline 298 & -1.47 & & & & \\
\hline 313 & 0.15 & \multicolumn{2}{|c|}{-33.62} & \multicolumn{2}{|c|}{-0.11} \\
\hline 333 & 2.30 & & & & \\
\hline
\end{tabular}

Table 3. Langmuir and Freundlich isotherm parameters and thermodynamic parameters for the removal of Congo red by pine bark.

higher $\mathrm{pH}$. Moreover, the band at $1614 \mathrm{~cm}^{-1}$ increased at natural $\mathrm{pH}$, whereas diminished slightly at $\mathrm{pH}=2$. The spectra before and after dye adsorption also indicate that the band at $1267 \mathrm{~cm}^{-1}$ corresponding to $-\mathrm{SO}_{3}$ group increased after adsorption. These changes suggested interactions between the functional groups of the bark and dye molecules as reported in literature ${ }^{18,32}$.

To understand the adsorption mechanism, it is necessary to determine the concentration of the surface-active groups, i.e. the point of zero charge $\left(\mathrm{pH}_{\mathrm{PZC}}\right)$ of the adsorbent. Thus, the $\mathrm{pH}_{\mathrm{PZC}}$ of the bark was found to be 3.4. This means that the adsorption of cationic forms is favoured at $\mathrm{pH}>\mathrm{pH}_{\mathrm{PZC}}$ as the surface is negatively charged, whereas anion adsorption is favoured at $\mathrm{pH}<\mathrm{pH}_{\mathrm{PZC}}{ }^{32}$. Therefore, it is expected that low $\mathrm{pH}$ favours the removal of Congo red since it's an anionic dye.

Stability of CR dye solutions. The degradation of Congo red and the influence of pH in the UV-Vis absorption, previously reported ${ }^{33}$, have been confirmed.

To analyse the colour change and stability with time of aqueous Congo red solutions at various initial concentrations, stability tests at two of the $\mathrm{pH}$ essayed (natural and 2) were performed, avoiding the $\mathrm{pH}$ range between 2.3 and 4 corresponding to the dye transition zone. As shown in Fig. 2a, the colour is stable for 7 days at the natural $\mathrm{pH}$ and low initial concentrations (below $50 \mathrm{mg} \mathrm{L}^{-1}$ ). However, at the highest concentration, the absorbance of the main band of the spectrum decreased markedly with time. At $\mathrm{pH} 2$, a pronounced shift and a significant decrease in the absorbance of the main absorption band were observed (Fig. 2b-d). This behaviour was more evident when the dye concentration increased, and it is probably related to the formation of molecular aggregates of $\mathrm{CR}^{18}$. Accordingly, adsorption kinetic experiments were conducted at the lowest initial concentration essayed $\left(5 \mathrm{mgL}^{-1}\right)$.

Adsorption kinetics experiments. Effect of initial solution $\mathrm{pH}$ on $\mathrm{CR}$ adsorption. $\mathrm{pH}$ affects the adsorption behaviour of the systems essayed, increasing or decreasing the adsorption capacity, because it modifies the ionization state of the binding groups of both adsorbate and adsorbent, as mentioned before. Therefore, it is 
necessary to determine the best $\mathrm{pH}$ for $\mathrm{CR}$ adsorption by pine bark. Thus, experiments were performed at $\mathrm{pH}$ from 2 to 9, using an initial dye concentration of $5 \mathrm{mg} \mathrm{L}^{-1}$, a solid/liquid ratio of $10 \mathrm{~g} \mathrm{~L}^{-1}$ and a temperature of $25^{\circ} \mathrm{C}$. As seen from Fig. 3a the highest adsorption rate was attained at $\mathrm{pH}=2$, whereas at $\mathrm{pH}=9$ adsorption was much slower, which implied that at least seven days were necessary for guaranteeing adsorption equilibrium.

According to the point of zero charge of 3.4 found for pine bark, the predominant functional groups are anionic at alkaline $\mathrm{pH}$, whereas at acid $\mathrm{pH}$ the charges are positive. Moreover, the isoelectric point of Congo red is 3 , and, therefore, its molecular structures are predominantly negative at $\mathrm{pH}>3$, being in non-dissociated and cationic forms at $\mathrm{pH}<\mathrm{pH}_{\mathrm{PZC}}$. That is, at the two low $\mathrm{pH}$ essayed (natural and 2) the participation of electrostatic interactions between the bark surface and Congo red will be negligible, mainly due to the repulsion between similarly charged molecules ${ }^{18}$.

The maximum equilibrium adsorption capacity of $0.47 \mathrm{mg} \mathrm{g}^{-1}$ corresponding to almost $100 \%$ of removal efficiency was achieved at $\mathrm{pH}=2$ (Fig. 3a,b). Usually, the adsorption anionic dyes, such as Congo red, increases as the $\mathrm{pH}$ decreases. Thus, at the highest $\mathrm{pH}$ essayed $(\mathrm{pH}=9)$, both the removal efficiency and the equilibrium adsorption capacity decreased to $61.7 \%$ and $0.3 \mathrm{mgg}^{-1}$, respectively. The removal efficiencies at equilibrium were higher than those found for Pinus radiata cone biomass of 60.5 and $5.75 \%$ at $\mathrm{pH}$ of 3.55 and 10.95, respectively, for an initial concentration of $20 \mathrm{mg} \mathrm{L}^{-1}$ at $30^{\circ} \mathrm{C}$ and an equilibrium time considerably lower, within $100 \mathrm{~min}^{17}$. Apart from the negative charge on the bark surface, the $\mathrm{OH}^{-}$ions compete for the adsorption sites ${ }^{17,18,20}$. In acid conditions, probably, the hydrophobic and van der Waals interactions and $\mathrm{H}$-bonding become dominant in the adsorption mechanism ${ }^{34}$.

The experimental data were analysed by the pseudo-first-order and pseudo-second-order kinetic models. As seen in Fig. 3b, the experimental data were well fitted by the pseudo-second-order model $\left(R^{2}>0.98\right)$. The model parameters together with the correlation coefficients are shown in Table 2 . As can be proved, the predicted values for $\mathrm{q}_{\mathrm{e}}$ were close to the experimental ones. On the contrary, the pseudo-first-order model did not apply well for all $\mathrm{pH}$ essayed $\left(0.93>\mathrm{R}^{2}>0.81\right)$. This result suggested that the overall rate of CR adsorption could be controlled by chemical processes between CR and Pinus pinaster bark ${ }^{35}$.

Additionally, to identify the diffusion mechanism, adsorption data were analysed using the intra-particle diffusion model (Eq. 6). As shown in Fig. 4, multilinearity was found for all pHs, which confirmed the occurrence of multiple adsorption stages, external mass transfer followed by intra-particle diffusion. Dye molecules were quickly transported to the bark external surface through film diffusion. After that, dye molecules entered the pores of pine bark by intra-particle diffusion in a slower step, as confirmed by the $\mathrm{K}_{\mathrm{id}}$ values (Table 2). It can be concluded that intra-particle and external diffusion occurred simultaneously ${ }^{36}$.

Effect of the adsorbent dosage. The effect of pine bark dosage, which was varied from 1 to $10 \mathrm{~g} \mathrm{~L}^{-1}$, on CR adsorption was studied at $25^{\circ} \mathrm{C}$ with a Congo red solution of $5 \mathrm{mg} \mathrm{L}^{-1}$ at the two $\mathrm{pHs}$ leading to the highest dye removal, 2 and natural $\mathrm{pH}$. The kinetic behaviour was also well represented by the pseudo-second-order model (Fig. 5a,b and Table 2), which confirmed that the adsorbent dosage did not influence the adsorption mechanism.

As shown in Fig. 5c,d, increasing pine bark dosage significantly improved CR removal efficiency, from 29.4 to $77.4 \%$ at natural $\mathrm{pH}$ and from 23.4 to $100 \%$ at $\mathrm{pH}$ 2. This behaviour can be explained by the greater number of active sites when the amount of adsorbent is increased ${ }^{16}$. On the contrary, it has been found that the adsorption capacity decreased when the adsorbent dosage was increased as shown in Fig. 5a,b for both pHs. Additionally, when decreasing the adsorbent dosage the equilibrium sorption capacity $\left(\mathrm{q}_{\mathrm{e}}\right)$ was lower than the expected maximum capacity (Table 2 ). This behaviour can be explained by the lower dye concentration that hinders adsorbent-adsorbate interactions ${ }^{37}$.

Effect of temperature on dye adsorption kinetics. The effect of temperature (in the range $25-60^{\circ} \mathrm{C}$ ) on CR adsorption by pine bark was studied using a CR solution of $5 \mathrm{mg} \mathrm{L}^{-1}$ at the natural $\mathrm{pH}$ of the solution and an adsorbent dosage of $10 \mathrm{~g} \mathrm{~L}^{-1}$. Natural $\mathrm{pH}$ was selected for studying the influence of temperature as provided a relatively high adsorption rate and more stable solutions than $\mathrm{pH}=2$. A slight influence of temperature on the removal of $\mathrm{CR}$ by Pinus pinaster bark was observed (Fig. 6). Thus, the adsorption capacity decreased with increasing temperature from $25^{\circ} \mathrm{C}$ to $60^{\circ} \mathrm{C}$, which indicates that the process is exothermic.

Thermodynamic studies. The thermodynamic behaviour for the adsorption of CR on pine bark was investigated. Thermodynamic parameters such as the Gibb's free energy $\left(\Delta \mathrm{G}^{\circ}\right)$, entropy $\left(\Delta \mathrm{S}^{\circ}\right)$ and enthalpy $\left(\Delta \mathrm{H}^{\circ}\right)$ changes were calculated by Eqs (7) and (8) and their values are presented in Table 3 . The negative value of $\Delta \mathrm{G}^{\circ}$ at $25^{\circ} \mathrm{C}$ indicated the feasibility and spontaneity of $\mathrm{CR}$ adsorption on pine bark, being less favoured at higher temperatures. Additionally, the value of $\Delta \mathrm{H}^{\circ}<84 \mathrm{~kJ} / \mathrm{mol}$ confirmed that the adsorption was physical ${ }^{18}$. As a result, the weakening of hydrogen bonds and van der Waals interactions at higher temperatures resulted in the weakening of physical interactions between the active sites of pine bark and the dye, decreasing the removal efficiency ${ }^{38}$. The negative value of $\Delta S^{\circ}$ suggested a decrease in randomness at the solid/liquid interface, and that no significant changes occurred in the internal structure of pine bark during CR adsorption. The negative value of $\Delta \mathrm{H}^{\circ}$ indicated the exothermic nature of adsorption, as mentioned above.

Arrhenius equation rearranged to a linear relationship between the rate constant and temperature, as shown by Eq. 12, was applied to determine the activation energy of the adsorption process $\left(E_{a}\right)$ :

$$
\ln k_{2}=\ln A-\frac{E_{a}}{R T}
$$

where $\mathrm{A}$ is the Arrhenius factor, $\mathrm{R}$ is the ideal gas constant and $\mathrm{T}$ is temperature $(\mathrm{K})$. The value of the activation energy, $23.9 \mathrm{~kJ} \mathrm{~mol}^{-1}$, lower than $40 \mathrm{~kJ} \mathrm{~mol}^{-1}$, confirms the physisorption of CR on pine bark ${ }^{39}$. 
Adsorption equilibrium isotherm. In this study, two of the most widely used isotherms, Freundlich and Langmuir models, were used for describing experimental equilibrium data for Congo red adsorption on pine bark at $25^{\circ} \mathrm{C}$, natural $\mathrm{pH}$ and adsorbent dosage of $10 \mathrm{~g} \mathrm{~L}^{-1}$. Both isotherms (Eqs 9 and 11) fitted well the data in terms of correlation coefficients, although the Freundlich model gave a slightly better fit (Table 3), indicating that adsorption occurs on a heterogeneous surface. The value of $n>1$ indicates that the adsorption is favourable at $25^{\circ} \mathrm{C}$. The $\mathrm{R}_{\mathrm{L}}$ value (Eq. 10), which was determined using the parameters of the Langmuir isotherm for the initial concentration of $5 \mathrm{mg} \mathrm{L}^{-1}$, is between 0 and $1(0.43)$, therefore, Pinus pinaster bark is confirmed as a favourable adsorbent for Congo red dye.

\section{Conclusion}

Congo red adsorption by pine bark depended strongly on $\mathrm{pH}$. $\mathrm{pH}$ affected not only the surface charges on the adsorbent but also the stability of Congo red solutions related with the formation of aggregates of the dye molecules. This was more evident when $\mathrm{pH}$ was decreased and when initial dye concentration was increased. Apart from $\mathrm{pH}$, adsorption percentage and capacity were influenced by adsorbent dosage and temperature. Natural pH provided the highest adsorption rate, stable dye solutions and satisfactory adsorption yields. The adsorption of Congo red by pine bark was demonstrated by the morphological changes in the bark surface and the changes in intensities and shifts of some functional groups in the FTIR spectra. It was found that Congo red adsorption by pine bark followed the pseudo-second-order kinetic model and that intra-particle and external diffusion occurred simultaneously. Freundlich isotherm provided the best fit to the experimental data showing a heterogeneous and multi-layer adsorption. Finally, thermodynamic analysis indicated that Congo red adsorption was a spontaneous, exothermic and a physical process in nature. This work demonstrated the capacity of water-treated pine bark for the removal of Congo red from aqueous solutions. However, although high adsorption percentages were achieved, the time needed to reach equilibrium was too long compared to other biomass adsorbents. Therefore, alternative pretreatments for pine bark must be tested in order to increase adsorption rate and efficiency.

Received: 14 March 2019; Accepted: 28 October 2019;

Published online: 11 November 2019

\section{References}

1. Ravi, K., Deebika, B. \& Balu, K. Decolourization of aqueous dye solutions by a novel adsorbent: application of statistical designs and surface plots for the optimization and regression analysis. J. Hazard. Mater. B122, 75-83 (2005).

2. McMullan, G. et al. Microbial decolourisation and degradation of textiles dyes. Appl. Microbiol. Biot. 56, 81-87 (2001).

3. Lee, J. W., Choi, S. P., Thiruvenkatachari, R., Shim, W. G. \& Moon, H. Evaluation of the performance of adsorption and coagulation processes for the maximum removal of reactive dyes. Dyes Pigments 69, 196-203 (2006).

4. Yao, Z., Wang, L. \& Qi, J. Biosorption of methylene blue from aqueous solution using a bioenergy forest waste: Xanthoceras sorbifolia seed coat. Clean-Soil Air Water 37, 642-648 (2009).

5. Sen, T. K., Afroze, S. \& Ang, H. M. Equilibrium, kinetics and mechanism of removal of methylene blue from aqueous solution by adsorption onto pine cone biomass of Pinus radiata. Water Air Soil Pollut. 218, 499-515 (2011).

6. Tan, I. A. W., Hameed, B. H. \& Ahmad, A. L. Equilibrium and kinetic studies on basic dye adsorption by oil palm fibre activated carbon. Chem. Eng. J. 127, 111-119 (2007).

7. Ghaly, A. E., Ananthashankar, R., Alhattab, M. \& Ramakrishnan, V. V. Production, characterization and treatment of textile effluents: a critical review. J. Chem. Eng. Process Technol. 5, 1-19 (2014).

8. Chen, K. C., Wu, J. Y., Huang, C. C., Liang, Y. M. \& Hwang, S. C. J. Decolorization of azo dye using PVA-immobilized microorganisms. J. Biotechnol. 101, 241-252 (2003).

9. Gong, R. et al. Utilization of powdered peanut hull as biosorbent for removal of anionic dyes from aqueous solution. Dyes Pigments 64, 187-192 (2005).

10. Chen, H. \& Zhao, J. Adsorption study for removal of Congo red anionic dye using organo-atapulgite. Adsorption 15, 381-389 (2009).

11. Elahmadia, M. F., Bensalahb, N. \& Gadria, A. Treatment of aqueous wastes contaminated with Congo red dye by electrochemical oxidation and ozonation processes. J. Hazard. Mater. 168, 1163-1169 (2009).

12. Li, C., Lingling, F., Xinlai, W., Jie, J. \& Ke, W. Study on the adsorption characteristics of Congo red by sycamore bark activated carbon. Environ. Technol. Resour. I, 64-69 (2017)

13. Srinivasan, A. \& Viraraghavan, T. Decolourization of dye wastewaters by biosorbent: a review. J. Environ. Manage. 91, 1915-1929 (2010).

14. Kyzas, G. Z., Lazaridis, N. K. \& Kostoglou, M. On the simultaneous adsorption of a reactive dye and hexavalent chromium from aqueous solutions onto grafted chitosan. J. Colloid Interface Sci. 407, 432-441 (2013).

15. Cheng, Z., Zhang, L., Guo, X., Jiang, X. \& Li, T. Adsorption behavior of direct Red 80 and Congo red onto activated carbon/ surfactant: process optimization, kinetics and equilibrium. Spectroc. Acta Pt. A-Molec. Biomolec. Spectr. 137, 1126-1143 (2015).

16. Salleh, M. A. M., Mahmoud, D. K., Karim, W. A. \& Idris, A. Cationic and anionic dye adsorption by agricultural solid wastes: a comprehensive review. Desalination 280, 1-13 (2011).

17. Dawood, S. \& Sen, T. K. Removal of anionic dye Congo red from aqueous solution by raw pine and acid-treated pine cone powder as adsorbent: equilibrium, thermodynamic, kinetics, mechanism and process design. Water Res. 46, 1933-1946 (2012).

18. Yaneva, Z. L. \& Georgieva, N. V. Insights into Congo rerd adsorption on agro-industrial materials-Spectral, equilibrium, kinetic, thermodynamic, dynamic and desorption studies. I.RE.CH. E. 4, 127-146 (2012).

19. Velkova, Z. Y., Kirova, G. K., Stoytcheva, M. S. \& Gochev, V. K. Biosorption of Congo red and methylene blue by pretreated waste Streptomyces fradiae biomass - Equilibrium, kinetic and thermodynamic studies. J. Serb. Chem. Soc. 83, 107-120 (2018).

20. Zhou, Y., Ge, L., Fan, N. \& Xia, M. Adsorption of Congo red from aqueous solution onto shrimp shell powder. Adsorpt. Sci. Technol. 36, 1310-1330 (2018).

21. Vázquez, G., González-Álvarez, J., Freire, S., López-Lorenzo, M. \& Antorrena, G. Removal of cadmiun and mercury ions from aqueous solution by sorption on treated Pinus pinaster bark: Kinetics and isotherms. Bioresour. Technol. 82, 247-251 (2002).

22. Vázquez, G., González-Álvarez, J., García, A. I., Freire, M. S. \& Antorrena, G. Adsorption of phenol on formaldehyde-pretreated Pinus pinaster bark: equilibrium and kinetics. Bioresour. Technol. 98, 1535-1540 (2007).

23. ASTM D1102 - 84. Standard Test Method for Ash in Wood (2013).

24. Moreno-Castilla, C., López-Ramón, M. V. \& Carrasco-Marín, F. Changes in surface chemistry of activated carbons by wet oxidation. Carbon 38, 1995-2001 (2000).

25. Ho, Y. S. \& McKay, G. Pseudo-second order model for sorption process. Process Biochem. 34, 451-465 (1999). 
26. Weber, W. J. \& Morris, J. C. Kinetics of adsorption on carbon from solution. J. Sanit. Eng. Div. 89, 31-60 (1963).

27. Langmuir, I. Adsorption of gases on plane surfaces of glass, mica and platinum. J. Am. Chem. Soc. 40, 1361-1403 (1918).

28. Freundlich, H. Über die adsorption in lösungen. J. Phys. Chem. A57, 385-470 (1906).

29. Nelly, J. W. \& Isacoff, E. G. Carbonaceous adsorbents for the treatment of ground and surface water, Marcel Dekker, New York (1982).

30. Santhi, T., Manonmani, S. \& Smitha, T. Removal of malachite green from aqueous solution by activated carbon prepared from the epicarp of Ricinus communis by adsorption. J. Hazard. Mater. 179, 178-186 (2010).

31. Sharma, A., Siddiqui, Z. M., Dhar, S., Mehta, P. \& Pathania, D. Adsorptive removal of congo red dye (CR) from aqueous solution by Cornulaca monacantha stem and biomass-based activated carbon: isotherm, kinetics and thermodynamics. Sep. Sci. Technol. 54, 916-929 (2019).

32. Wang, L. \& Wang, A. Adsorption properties of Congo red from aqueous solution onto N, O- carboxymethyl-chitosan. Bioresour. Technol. 99, 1403-1408 (2008).

33. Zhou, Q., Xie, C., Gong, W., Xu, N. \& Zhou, W. Comments on the method of using maximum absorption wavelength to calculate Congo Red solution concentration. J. Hazard. Mater. 198, 381-382 (2011).

34. Ahmad, R. \& Kumar, R. Adsorptive removal of Congo red dye from aqueous solution using bael shell carbon. Appl. Surf. Sci. 257, $1628-1633$ (2010).

35. Wanyonyi, W. C., Onyari, J. M. \& Shiundu, P. M. Adsorption of Congo red dye from aqueous solutions using roots of Eichhornia crassipes: kinetic and equilibrium studies. Energy Procedia 50, 862-869 (2014).

36. Garg, V. K., Kumar, R. \& Gupta, R. Removal of malachite green dye from aqueous solution by adsorption using agro-industry waste: a case study of Prosopis cineraria. Dyes Pigments 62, 1-10 (2004).

37. Fegousse, A., El Gaidoumi, A., Miyah, Y., El Mountassir, R. \& Lahrichi, A. Pineapple bark performance in dyes adsorption: optimization by the central composite design. J. Chem. 2019, https://doi.org/10.1155/2019/3017163 (2019).

38. Hu, Z., Chen, H., Ji, F. \& Yuan, S. Removal of Congo red from aqueous solution by cattail root. J. Hazard. Mater. 173, 292-297 (2010).

39. Rahchamani, J., Moausavi, H. Z. \& Behzad, M. Adsorption of methyl violet from aqueous solution bypolyacrylamide as an adsorbent: Isotherm and kinetic studies. Desalination 267, 256-260 (2011).

\section{Acknowledgements}

Authors want to thank the Erasmus Mundus Maghreb and Egypte-Emmag program for a grant awarded to Khaoula Litefti.

\section{Author contributions}

The manuscript was written through contributions of all authors. All authors have given a proval to the final version of the manuscript. Provided the resources, conceived and designed the experiments: J.G.A. and M.S.F. Performed the experiments: K.L. Research supervision: J.G.A. and M.S.F. Analyzed the data: J.G.A., M.S., M.S.F. and K.L. Preparation of the manuscript and critical review: J.G.A., M.S.F., M.S. and K.L.

\section{Competing interests}

The authors declare no competing interests.

\section{Additional information}

Correspondence and requests for materials should be addressed to J.G.-A.

Reprints and permissions information is available at www.nature.com/reprints.

Publisher's note Springer Nature remains neutral with regard to jurisdictional claims in published maps and institutional affiliations.

(c) (i) Open Access This article is licensed under a Creative Commons Attribution 4.0 International License, which permits use, sharing, adaptation, distribution and reproduction in any medium or format, as long as you give appropriate credit to the original author(s) and the source, provide a link to the Creative Commons license, and indicate if changes were made. The images or other third party material in this article are included in the article's Creative Commons license, unless indicated otherwise in a credit line to the material. If material is not included in the article's Creative Commons license and your intended use is not permitted by statutory regulation or exceeds the permitted use, you will need to obtain permission directly from the copyright holder. To view a copy of this license, visit http://creativecommons.org/licenses/by/4.0/.

(C) The Author(s) 2019 